This tonic contraction with its concurrent shortening would be quite enough to produce the rigidity necessary for syphon action, and it cannot be denied that the large intestine with its short ascending and long descending tube fulfils in other respects the conditions of a syphon.

One of my points was that, on completely filling the colon by injection from the cut ileum, the 20 -inch transverse colon leaves its nine-inch bed and becomes elongated and tortuous; the same thing must happen in sigmoid obstruction. Thus the question arises: Is the V-shaped colon sometimes a post-mortem change? When a person is found dead in a sitting position, therefore, I should like the maker of the necropsy to notice whether the transverse colon has dropped from its usual site. If empty perhaps this could not be expected. Again, $I$ have a suspicion that the constipation and colic of lead poisoning are due to paralysis of the longitudinal bands with the consequent elongation, kinking, and loss of rigidity of the bowel. This should not be very difficult to determine. Further, since $I$ have shown that hydraulic power is a factor in the propulsion of the intestinal contents, I should like to know with what average force the stream from the ileum enters the cæcum.

I am, Sirs, yours faithfully,

Buckingham-gate, S.W., Feb. 9th, 1903.

$$
\text { R. W. LEFTWIOH, M.D. }
$$

\section{THE UNIVERSITY OF LONDON AND THE ENGLISH ROYAL COLLEGES OF PHYSICIANS AND SURGEONS.

\author{
To the Editors of THE LANCET.
}

SIRs, - I would like to make a few remarks upon "Africander's" letter in THe LANCET of Feb. 7th, p. 399. He states that: "Hitherto the whole crux of the question has been taken to be not a matter of personal ability but of opportunity," and I quite agree with him. I contend that opportunity should exist in London, as in other university towns. It seems anomalous that out of 60 entries at a London hospital only four should contemplate taking a degree. I submit that out of the same number of students entering, say, at Edinburgh, a very much larger percentage would contemplate and, as a matter of fact, take the degree. Further, however judicial the mind of South Africa is in respect to the practitioner of medicine (a country by the bye just now perturbed by political and racial hatred), there is I submit a very great advantage in possessing a degree in the old country, and the opportunity to obtain the same in London would be forthcoming were the Royal Colleges to join the University for examination purposes under the Act of Parliament which contemplated the possible desirability of such a union.

I am, Sirs, yours faithfully, FREDK. W. COLIINGWOOD.

Devonshire-street, W., Feb. 7th, 1903.

\section{NOTES FROM INDIA.}

\section{(From OUR SPecial OORRespondent.)}

Mr. Jonathan Hutohinson's Leprosy Tour.-The Jamsetjee Jejeebhoy Native Hospital in Bombay.-The Government Grant to the Pasteur Institute at Kasauli.-The Plague Epidemic.

THE advent of Mr. Hutchinson to the principal cities of India is announced by letters in the local papers. Besides asking for information and promising to attend meetings Mr. Hutchinson gives a résumé of his views upon leprosy. He holds that the disease is caused by a bacillus which gains access to the body through the stomach, that there is great danger in eating food directly from the hands of a leper, that in the majority of grown-up lepers the disease is caused by eating badly-cured fish, and that a long period is necessary before results will be observed. It remains to be seen how the profession in India will receive these opinions which many consider are advanced on very imperfect scientific data.

The public appeal for money in aid of the nursing establishment of the Jamsetjee Jejeebhoy Native Hospital in Bombay is accompanied by the announcement of an extraordinary condition of the nursing staff. Here we have the largest native hospital in Bombay of no less than 460 beds which are always full, with 15 wards totally unnursed and seven others only nursed during the day. There is no complaint about the buildings and the staff is for the most part drawn from the Indian Medical Service. Treatment can hardly be conducted with much satisfaction to the medical men and the patients are without one of the main advantages of a hospital. It is stated that the Bombay Government is prepared to assist to the extent of half the expenditure necessary.

The increase in the Government of India grant to the Pasteur Institute at Kasauli is not marked by excessive liberality. Hitherto Rs. 9500 have been contributed, but in future Rs. 12,000 have been promised. Considering that 119 European and 33 native military patients were treated last year and that if the institute had not been established a very much larger sum than the above would have been incurred in sending British soldiers to Paris, the apparent generosity is in reality a sharp stroke of business. The institute is dependent in part upon private subscriptions and is necessarily hampered in its work by uncertainty in income. As other scientific work than the treatment of rabies is conducted at this institute it is of the highest importance that its expenses should be completely covered and Rs. 20,000 at least should be the annual grant made from the Government of India alone.

Every week now records rapidly rising figures in the plague mortality throughout India. Last week 22,954 deaths were recorded, as compared with 19,231 for the previous seven days and with 11,445 for the corresponding week last year. In the Bombay Presidency 10,747 deaths were returned, in Bombay city 495, in the Madras Presidency 848, in the Bengal Presidency 3060, in Calcutta 76, in the United Provinces 2954, in the Punjab 2627, in the Central Provinces 850, in the Hyderabad State 446, and in Berar 596. For some extraordinary reason the Poona figures are not included in the published returns, but local papers show that it is raging in this town with extraordinary virulence, over 100 deaths occurring daily. The disease is still severe in Karachi and is also severe in Allahabad, Meerut, Benares, and Lucknow, while the Cawnpore district continues to suffer very badly. In Bombay city the rate of mortality is about 90 per 1000 per annum. In Calcutta the recrudescence is rapidly developing. Madras has shown some indigenous cases and other cases are reported from Simla.

The mass of poor humanity which assembled in Calcutta upon the large Maidan to be fed in celebration of the King's Coronation numbered probably 50,000. The wretched physique of the majority of these beggars was painfully evident and the collection offered many opportunities of seeing external diseased conditions. Skin diseases were very common, especially the different forms of parasitic origin, and numerous lepers moved amongst the crowd. Deformities, paralytic states, and conditions produced by chronic diseases such as malaria and elephantiasis were everywhere evident. The Hindu portion consisted largely of professional beggars. A few years ago such a gathering would have been condemned as conducive to the spread of plague, but subsequent knowledge has shown that a plague patient would be either too ill to go or not in a stage of contagion.

Jan. 30th.

Literary Inteldigence.-The Scientific Press, Limited, announces the publication of a cheap edition, price 10s. 6d. net, of Dr. R. Sisley's work, "The London WaterSupply." Messrs. W. B. Saunders and Co. announce the immediate publication of two new volumes in "Saunders's Medical Hand Atlas Series"-viz,, "Atlas and Epitome of Diseases of the Mouth, Pharynx, and Nose," by Dr. L. Grünwald of Munich, edited, with additions, by Dr. J. E. Newcomb ; and "Atlas and Epitomeof Human Histology and Microscopical Anatomy," by Professor Dr. J. Sobotta of Würzburg, edited, with additions, by Dr. G. C. Huber. Messrs. Saunders and Co. have in preparation for early publication two new volumes in their English edition of Nothnagel's Practice-viz, "Diseases of the Pancreas, Suprarenal Capsules, and Liver," and "Diseases of the Stomach."-Mr. Henry Frowde announces the approaching publication by the Oxford University Press of Dr. A. J. Ewart's treatise on "The Physics and Physiology of Protoplasmic Steaming in Plants," of which an abstract was communicated to the Royal Society. 